\section{Life, Death, Transitions}

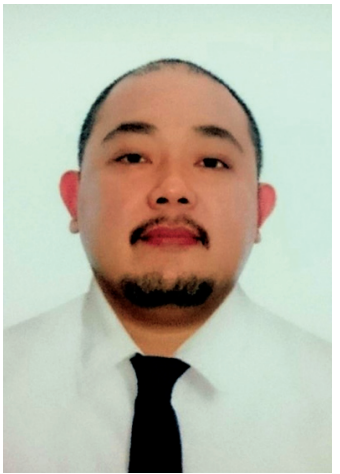

I am sharing with you the first issue of the Philippine Journal of Pathology for 2021, our tenth issue since we breathed life into our society publication in 2016 . We have two case reports of gynecologic tumors, and an autopsy case of a disseminated hematolymphoid malignancy. Four original articles include a molecular pathology study for lung cancer, a real-world observational study on pooled testing among asymptomatic individuals, a cost effectiveness study on diagnostics for leukemia in the Philippines, and a 5-year soft tissue tumor review. On top of these, we are featuring a new section Opinion, and we have on board, Dr. Raymundo Lo, to regularly provide his take on issues relevant to our profession and practice. This issue also comes alive with the inclusion of the entries and winners of the PSP 69 th Annual Convention Photomicroscopy Contest sponsored by Omnibus Biomedical Systems.

Much has happened and is happening in this ongoing battle with COVID-19, the evolution of the national response, from surveillance to diagnostics to treatment, and now to immunization, the worrisome evolution and spread of variants of concern, the latest of which is the delta variant from South Asia, from the New Normal to the Next Normal and hopefully to the Better Normal.

On a personal note, however, no other event is more impactful to me than the loss of a mentor and friend, a beloved pathologist, and our adviser for the PJP, Dr. Jose Ma. C. Avila (Figure 1). It was he who helped us initiate efforts to revive our journal, and I can clearly remember him asking me in his straightforward booming voice, "do you even have anything to publish?" We dedicate this issue to him to celebrate his life and his transition to the next.

Early on, we knew that the government reference laboratory and its handful of subnational laboratories, cannot provide the scale of testing needed for the pandemic without the help of the other government laboratories and those in the private sector. The last time I saw Dr. Joey face to face was when we were visiting Makati Medical Center to activate their molecular laboratory for COVID-19 testing. The last time I was able to talk to him was around the third quarter of 2020, when they were running short of viral transport media. He ended the call by encouraging me to endure, as by then my office faced so many logistic challenges and political pressures due to the weaknesses of the national laboratory response. His words, "you are doing a great job, under the circumstances," meant a lot and kept me afloat, among other things.

Two years ago, I wrote a management case on the national reference laboratory surge capacity response to a massive nationwide measles outbreak in the Philippines.' This was part of the requirements for my public management development course at the Development Academy of the Philippines, was subsequently presented to a panel, and was eventually published in our journal. Surge is defined as "a sizable increase in demand for resources compared with a baseline demand"2 further described as "sudden, unanticipated escalations...caused by exceptional events." 3 On the other hand, surge capacity, is the ability to "manage a sudden or rapidly progressive influx... within the currently available resources at a given point in time,"3 and further as the "ability to effectively and rapidly expand capacity" 3 in recognition of the fact that surge capacity relates not only to sufficiency of currently available resources but even the ability to effectively and rapidly expand capacity.

Kelen and McCarthy combined surge and surge capacity to introduce the concept of surge response capability (Figure 2) - which is the "ability of the surge capacity (i.e., resources that are available and can be made available) to accommodate the surge (i.e., demand for resources). ${ }^{2}$

Thus, when surge capacity exceeds surge, the surge response capability is greater than 1 (the operating unit can respond effectively); however, when surge exceeds surge capacity, the surge response capability is less than 1 (the operating unit's systems will be challenged and may even fail to respond). The last equation attempts to dissect the determining factors for surge capacity (system [integrity], space [size, quality], staff [numbers, skill], supplies [volume, quality]) and surge (event [type, scale, duration], influx, resource demand [consumption, degradation]).

It is very glaring in the relationships described that planning exists as a common, major, and independent 


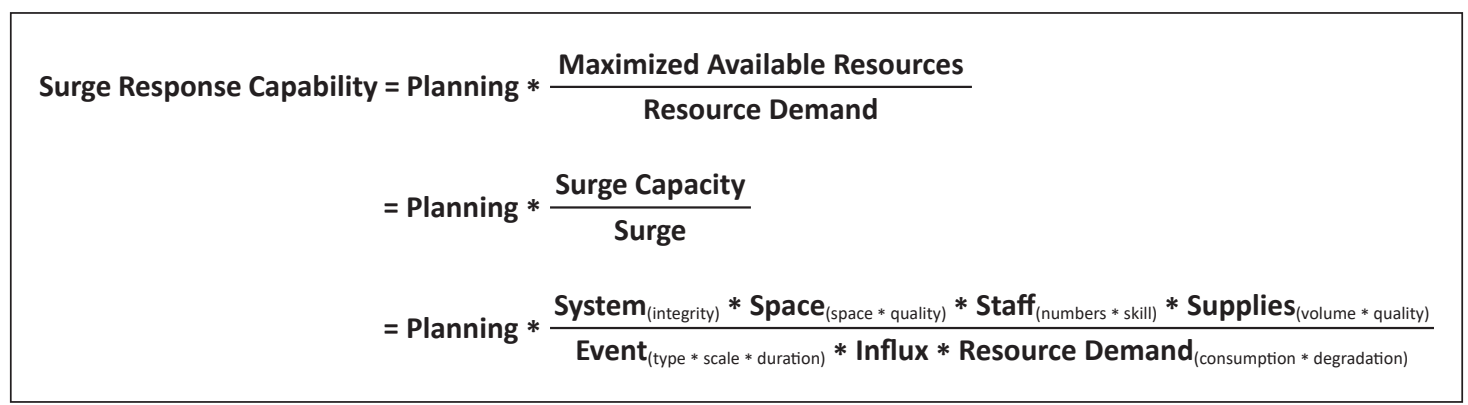

Figure 2. Functional relationship of surge response capability to surge capacity and surge (Adapted from Kelen and McCarthy, 2006). ${ }^{2}$

determinant of surge response capability. And yet the outbreaks of the past were not enough to stir us to really get down to business and plan for national health security. Dr. Lo, in his opinion piece, underscores the importance of learning our lessons and planning for the next pandemic, mentioning the pending bill on the creation of the Philippine Centers for Disease Control. Unfortunately, with the way discussions are going among lawmakers, the establishment of the CDC means the abolition of the very Institute that has stood its ground against this pandemic from Day 1, amid responding to other emerging and re-emerging threats. We can only hope that the powers-that-be can go beyond merging and dissolution of bureaus and offices, to purposively develop two things: a strong organization that can truly and capably function as the national public health institute, and a similarly strong network of laboratories that can be engaged readily as part of the country's surge capacity.

\section{Amado O. Tandoc III, MD, FPSP}

Editor-in-Chief

\section{REFERENCES}

1. Tandoc AO, Centeno RJ. National reference laboratory surge capacity response to a massive nationwide measles outbreak in 2013-2014. Philipp J Pathol. 2019;4(2):6-14. https://philippinejournalofpathology. org/index.php/ PJP/article/view/153.

2. Kelen GD, McCarthy ML. The science of surge. Acad Emerg Med. 2006; 13(11):1089-94. PMID:17085736. https://doi.org/10.1197/j.aem.2006.07.016.

3. Watson SK, Rudge JW, Coker R. Health systems' "surge capacity": state of the art and priorities for future research. Milbank Quarterly. 2013;91(1): 78-122. PMID:23488712. PMCID:PMC3607127. https://doi.org/10.1111/milq.12003.

https://doi.org/10.21141/PJP.2021.01 